\title{
Mechanical Properties of Steel Fiber Mixed Reactive Powder Concrete
}

\author{
Zhaopeng YANG \\ China Grain \& Logistics Corporation Beiliang Co., LTD \\ Eastern Project Department \\ Dalian, China \\ e-mail: yangzhaopeng@beiliang.com
}

\author{
$\mathrm{Lu} \mathrm{LU}$ \\ Dalian Jiaotong University \\ Liaoning Provincial Key Laboratory of New Energy Battery \\ Dalian, China \\ e-mail: piao0215@163.com
}

\begin{abstract}
Steel fiber with high elastic modulus, have been added to the reactive powder concrete (RPC) in order to improve its mechanical properties. In this paper, it is studied the impact of the change in the steel fiber content on compressive strength and flexural strength of hybrid fiber reinforced PRC. The results indicate that the mechanical properties of the steel fiber reinforced RPC can be improved to some extent.
\end{abstract}

Keywords-reactive powder concrete; steel fiber; mechanical properties

\section{INTRODUCTION}

Reactive powder concrete (RPC) is a kind of super-high strength, high durability, good volume stability of cementbased composite materials [1]. Not doped fiber RPC brittleness is large, the stress - strain relationship is close to a straight line, and there is little plastic deformation. Compression damage is suddenly burst type form. This undoubtedly brings to the RPC application engineering obstacles [2]. RPC (without fiber) material brittleness, and not by the nature of raw materials and cooperate with the ratios for improvement. RPC as a new type of cement base material, its composition similar mortar, so consider adopting the way of fiber reinforced. Fibre reinforced RPC, therefore, is the combination of fibers and high strength concrete, the reasonable use of fiber reinforced concrete with RPC, the characteristics of the ultra-high strength concrete is an ideal high performance concrete [3].

Marked by the engineering application, the current with the world's advanced countries such as France (RPC800 is strengthening research, etc.) there are 5 7 years gap [4, 5]. And RPC was just 15 years, so our priority must first successful application in actual engineering, and before application, there is a lot of hard work to do, this is the meaning of this topic research topic.

Different raw material compound fiber RPC is applied in this article, and the effects of steel fiber, glass fiber and polypropylene fiber on the mechanical behavior of plain RPC enhancement effect [6]. Hope that the improvement of the research on mechanical properties of RPC system to do some useful work can make contribution to the engineering application of the future.

\section{EXPERIMENTAL}

Cement: dalian onoda co., LTD., production of China 52.5R ordinary Portland cement. Silica fume: Shanghai day kai silicon powder materials co., LTD., the production of silicon powder, the silica content is $82.22 \%$. Fly ash: dalian huaneng power plant production grade I fly ash. Fine: using standard sand, fineness modulus of 1.8. Jianshuiji: dalian west card building materials co., LTD., production of west high efficiency water reducing agent. Steel fiber: dalian harvest metal fiber co., LTD. Production of cold-drawn steel fibre diameter $0.24 \mathrm{~mm}, 13 \mathrm{~mm}$ in length, the surface of the copper plating, the tensile strength of $800 \mathrm{MPa}$, the density of $7.8 \mathrm{~g} / \mathrm{cm}^{3}$, elastic modulus of 200GPa. Polypropylene fiber: sichuan zuoyue provided material technology co., LTD., the elastic modulus of $2.2 \mathrm{GPa}$.

\section{RESULTS AND DISCUSSION}

\section{A. The Change of Steel Fiber Volume Ratio on the Mechanical Properties of RPC}

In order to explore the standard of RPC under different steel fiber volume ratio of compressive strength, flexural strength and other physical and mechanical performance index, this paper conducted a series of 15 side length of 40 $\mathrm{mm} \times 160 \mathrm{~mm} \times 40 \mathrm{~mm}$ prism specimens of performance testing [7].

The addition of steel fiber concrete in aspects such as strength, toughness, plasticity increased significantly. Experiment shows that with the increase of steel fiber volume ratio, the properties of steel fiber reinforced concrete increase are more significant. Steel fiber is not, however, with the more the better: on the one hand, the steel fiber is expensive, the mixed too much will increase the project cost; Slender steel fiber, on the other hand, flexible, easy to cluster volume rate is too high, will not be able to give full play to its enhancement effect. In order to improve the enhancement effect of steel fiber and satisfy its construction performance, usually using of steel fiber length $\sim 60 \mathrm{~mm}$ to $10 \mathrm{~mm}$, diameter or equivalent diameter from $0.3 \mathrm{~mm}$ to $0.3 \mathrm{~mm}$, length to diameter ratio of $30 \sim 100$, the volume rate of $0.5 \%$ $\sim 2 \%$.

The mixture ratio of using table 2.1 , according to the test method of the first chapter, make specimen, maintenance, measuring flexural strength and compressive strength, snapping the prism compressive and flexural strength of the 
specimens values listed in table 1 . In the present experiment of steel fiber mixed volume rate is respectively: $0 \%, 0.5 \%$, $1 \%, 1.5 \%, 1 \%$, each volume rate under three groups of specimens, a total of 15 groups of specimens. Accurately measure the sizes of the specimen after, compressive strength, bending tested are as follows:

TABLE I. THE MechanicAl PROPERTIES OF STEEL Fiber RPC IN DIFFERENT VOLUME FRACTION

\begin{tabular}{|c|c|c|c|}
\hline Label & Steel Fiber & $\begin{array}{c}\text { Compressive } \\
\text { Strength } \\
\text { MPa }\end{array}$ & $\begin{array}{c}\text { Flexural } \\
\text { Strength } \\
\text { MPa }\end{array}$ \\
\hline A0 & S0 & 93.16 & 18.06 \\
\hline A1 & S0.5 & 95.06 & 19.12 \\
\hline A2 & S1 & 96.48 & 25.37 \\
\hline A3 & S1.5 & 119.89 & 34.82 \\
\hline A4 & S2 & 134.56 & 38.76 \\
\hline
\end{tabular}

\section{B. The Influence of Different Steel Fiber Volume Ratio to} the RPC Specimen Compressive Strength and Flexural Strengts

Specimen A0 - A4 compressive strength and flexural strength change were shown in figure 1 and figure 2 . In this group of specimens after adding steel fiber, compressive strength and flexural strength of RPC with the increase of steel fiber volume ratio, are on the rise. Incorporation of steel fiber on compressive strength of the specimens increased obviously higher than that of A0 compressive strength of specimen A4 nearly 40mpa, increased by nearly $45 \%$; Flexural strength increased nearly $20 \mathrm{MPa}$, increased by nearly $120 \%$. Thus, the greater the volume ratio of steel fiber (no more than 2\%), steel fiber on the stronger the effective restraint of reactive powder concrete, compressive strength increase is more obvious; The greater the volume ratio of steel fiber (no more than 2\%), on the shear plane constraint effect of steel fiber is, the more the higher the flexural strength of the specimens.

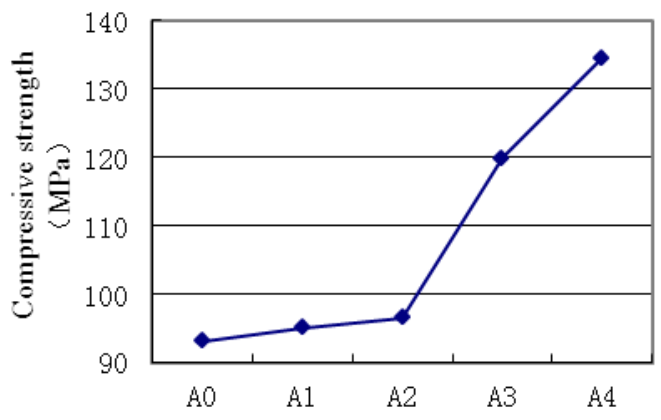

Figure 1. The influence of steel fiber's volume fraction change to compressive strength

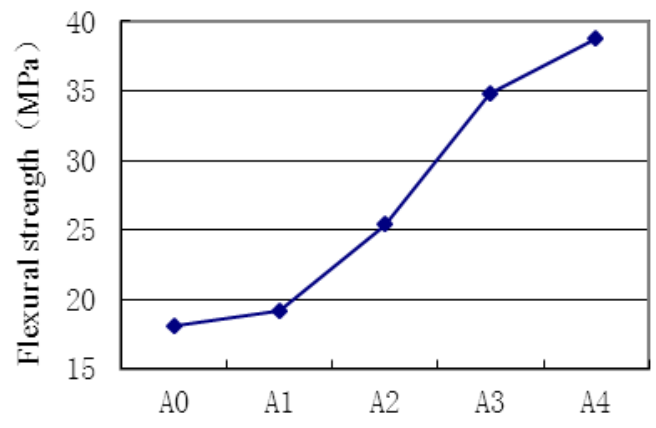

Figure 2. The influence of steel fiber's volume fraction change to flexural strength

\section{RPC Specimens under Different Steel Fiber Volume Ratio of Compression Ratio}

Folding ratio refers to the flexural strength of the specimens under the same mixture ratio and the ratio of axial compressive strength, its size reflects the bending capacity of concrete strength. Can be seen from table 2 RPC material discount ratio basically increases gradually along with the increase of steel fiber volume ratio.

Although the folding ratio represents the strength of the flexural performance, but not to fold the greater pressure than the bending capacity, the better; If the flexural strength is too big, under the condition of relatively low compressive strength, folding ratio is meaningless; Comparison is the premise of each group of compressive strength, bending strength of the specimens are separately on the rise or decline, the largest of the folding ratio set to reflect the group the strength of the specimen bending performance. And the increase of steel fiber volume ratio will increase the cost of ascension, and will increase the technology content in the construction, to sum up, this experiment A3 group (steel fiber volume content of $1.5 \%$ ) of specimen has excellent mechanical properties, it is the best material mix proportioning.

TABLE II. THE BEND-PRESS RATIO OF RPC COMPONENTS IN DIFFERENT STEEL FIBER's VOLUME FRACTION

\begin{tabular}{|c|c|c|c|c|c|}
\hline $\begin{array}{c}\text { Steel fiber volume } \\
\text { ratio (\%) }\end{array}$ & 0 & 0.5 & 1 & 1.5 & 2 \\
\hline $\begin{array}{c}\text { Flexural strength } \\
\text { (Mpa) }\end{array}$ & 18.06 & 19.12 & 25.37 & 34.82 & 38.76 \\
\hline $\begin{array}{c}\text { The compressive } \\
\text { strength (Mpa) }\end{array}$ & 93.16 & 95.06 & 96.48 & 119.89 & 134.56 \\
\hline $\begin{array}{c}\text { Fold the compression } \\
\text { ratio }\end{array}$ & $1 / 5.16$ & $1 / 4.97$ & $1 / 3.8$ & $1 / 3.44$ & $1 / 3.47$ \\
\hline
\end{tabular}

\section{The Change of Steel Fiber Volume Ratio on the Mechanical Properties of Fly Ash RPC}

In the need to improve the toughness of the RPC, then adding steel fiber. This experiment mainly through the change of the steel fiber volume ratio to test the RPC in the change of mechanical properties. 
The mixture ratio of using table 4.1, according to the test method of the first chapter, make specimen, maintenance, measuring flexural strength and compressive strength, snapping the prism flexural, compressive strength of the specimens values listed in table 4.1. This test USES $40 \mathrm{~mm}$ x $40 \mathrm{~mm} \times 160 \mathrm{~mm}$ prism specimens, a total of 5 kinds of steel fiber volume content: $0 \%, 0.5 \%, 1 \%, 1.5 \%, 1 \%, 3$ groups of specimens made of proportion of each, and accurately measure the size of the specimen after, compressive strength, bending strength measured data is as follows:

TABLE III. THE Mechanical PROPERTIES OF STEEL Fiber RPC IN DIFFERENT VOLUME FRACTION

\begin{tabular}{|c|c|c|c|}
\hline Label & Steel Fiber & $\begin{array}{c}\text { Compressive } \\
\text { Strength } \\
\text { MPa }\end{array}$ & $\begin{array}{c}\text { Flexural } \\
\text { Strength } \\
\text { MPa }\end{array}$ \\
\hline Af0 & S0 & 95.20 & 10.25 \\
\hline Af1 & S0.5 & 99.91 & 11.38 \\
\hline Af2 & S1 & 103.44 & 20.75 \\
\hline Af3 & S1.5 & 119.53 & 27.66 \\
\hline Af4 & S2 & 147.74 & 30.38 \\
\hline
\end{tabular}

\section{E. The Influence of Different Steel Fiber Volume Ratio to} the RPC Specimen Compressive Strength and Bending Strengts

The mixed with steel fiber, slurry mixing time longer, so that the steel fiber can evenly mixed in concrete as far as possible. When the fiber volume rate increased, the RPC fluidity decrease [8]. This major may be because of the arrangement of fibers in the pulp desultorily, while the number of fiber increased, some fiber will be staggered together and blocking effect. Mixed with steel fiber forming process of the specimens are relatively common specimens is difficult, the new add RPC can't insert, only vibration in the vibration or manual vibration close-grained. At the time of screeding is also easy to take out of the fiber in concrete, so need to be especially careful.

Specimen Af0-Af4 flexural strength and compressive strength change were shown in figure 3 and figure 4 . In this group of specimens, the flexural strength and compressive strength of RPC with the increase of steel fiber volume ratio, basic is rising trend. Incorporation of steel fiber on compressive strength of the specimens increased significantly, the specimen Af4 than Af0 nearly $50 \mathrm{MPa}$ compressive strength increase, namely increased by nearly $50 \%$; Flexural strength increased nearly $20 \mathrm{MPa}$, increased by nearly $200 \%$. In the process of the destruction of RPC, the specimen is usually destroyed by shear first, and then destroyed by compression. When the applied pressure to the shear strength of RPC matrix when crossing steel fiber to shear surface plus pressure produces all the tensile stress at the shear plane, thus enables the RPC to continue to bear the applied pressure and improved. The steel fiber volume ratio, the greater the constraints on the shear plane the function of steel fiber is, the more compressive strength, bending strength of the specimens are higher also.

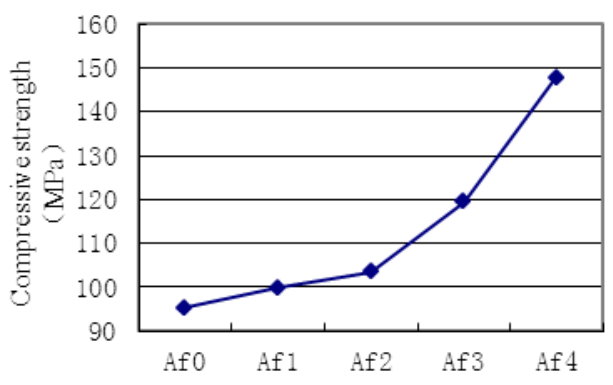

Figure 3. The influence of steel fiber's volume fraction change to compressive strength

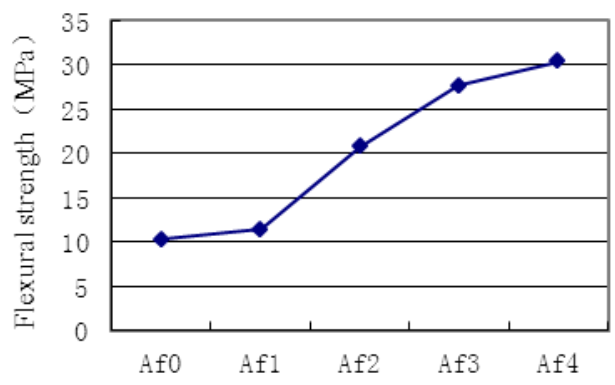

Figure 4. The influence of steel fiber's volume fraction change to flexural strength

\section{F. RPC Specimens under Different Steel Fiber Volume Ratio of Compression Ratio}

Folding ratio refers to the flexural strength of the specimens under the same mixture ratio and the ratio of axial compressive strength, its size reflects the bending capacity of concrete strength. Can be seen from table 4 RPC materials of compression ratio increases gradually along with the increase of steel fiber volume ratio.

TABLE IV. THE BEND-PRESS RATIO OF RPC COMPONENTS IN DIFFERENT STEEL FIBER'S VOLUME FRACTION

\begin{tabular}{|c|c|c|c|c|c|}
\hline $\begin{array}{c}\text { Steel fiber volume } \\
\text { ratio (\%) }\end{array}$ & 0 & 0.5 & 1 & 1.5 & 2 \\
\hline $\begin{array}{c}\text { Flexural strength } \\
\text { (Mpa) }\end{array}$ & 10.25 & 11.38 & 20.75 & 27.66 & 30.38 \\
\hline $\begin{array}{c}\text { The compressive } \\
\text { strength (Mpa) }\end{array}$ & 95.20 & 99.91 & 103.44 & 119.53 & 147.74 \\
\hline $\begin{array}{c}\text { Fold the } \\
\text { compression ratio }\end{array}$ & $1 / 9.29$ & $1 / 8.78$ & $1 / 5.0$ & $1 / 4.32$ & $1 / 4.86$ \\
\hline
\end{tabular}

Although the increase of steel fiber volume ratio, can improve the mechanical properties of RPC, but with too much are not necessarily can achieve project using the ideal effect. On the one hand, the increase of steel fiber volume ratio, raises the difficulty of RPC mixing and forming, even on the fiber and cement paste adhesive to form a New Deal. On the other hand, it will greatly increase the cost of production, against the RPC in the promotion of the market. From what has been discussed above, we believe that the 
steel fiber volume ratio with $1.5 \% 2 \%$ advisable. And from the table above shows that the steel fiber volume rate of $2.0 \%$ is the best.

\section{CONCLUSIONS}

In this paper, according to different raw materials of RPC, on the premise of consistent of proportion of raw materials, respectively, according to the appropriate adding steel fiber volume rate to make more groups of specimens. Through the test process and finally come up with the test data, can check through analysis and comparison of literature, can draw the following conclusion: separate mixed with steel fiber RPC, with the increase of steel fiber volume ratio, the mechanical properties of steel fiber reinforced concrete increase is more significant. Steel fiber, however, is not mixed, the better. The greater the volume ratio of steel fiber (no more than $2 \%$ ), steel fiber of reactive powder concrete effective constraint effect is stronger, the compressive strength increase is more obvious; The greater the volume ratio of steel fiber (no more than $2 \%$ ), on the shear plane constraint effect of steel fiber is, the more the higher the flexural strength of the specimens. Think of steel fiber volume ratio with $1.5 \%-2 \%$ advisable, steel fiber volume ratio of $2.0 \%$ is the best.

\section{ACKNOWLEDGMENT}

This research was funded by Liaoning Provincial Department of Education Program (Grant No. JDL2016013).

\section{REFERENCES}

[1] Lee Ming Gin, Wang Yung Chi,Chiu ChuiTe, "A preliminary study of reactive powder concrete as a new repairmaterial," Construction and Building Materials, vol. 21. 2007, pp.182-189.

[2] GreenM F, Bisby LA, BeaudoinY, et al , "Effect of freeze-thaw cycles on the bond durability between fiber reinforced polymer plate reinforcement and concrete," NRC Canada, J CivilEng, vol. 27, 2000, pp. 949-959.

[3] Olivier Bonneau, Mohamed Lachemi, Eric Dallaire, et al, "Mechanical Properties and Durability of Two Industrial Reactive Powder Concretes," ACI Materials Journal, vol. 94, 1997, pp. 286290.

[4] Marcel Cheyrezy, Vincent Maret, Laurent Frouin, "Microstructural Analysis of RPC (Reactive Powder Concrete)," Cement and Concrete Research, vol. 7, 1995, pp. 1491-1500.

[5] Dauriac, Christopher, "Special Concrete May Give Steel Stiff Competition," Seattle Daily Journal of Commerce, May 9, 1997.

[6] Pierre Richard, MarcelCheyrezy, "Composition of reactive powder concrete," Cementand Concrete Research, vol. 7, 1995, pp. 15011511.

[7] MatteV, MoranvilleV, "Durability ofReactive Powder Composites: influence of silica fume on the leaching properties of very low water/binder pastes," Cement and Concrete Composites, vol.6, 1999, pp. 1-9.

[8] Bayard O, Ple O, "Fracture mechanics of reactive powder concrete: materialmodeling and experimental investigations," Engineering Fracture Mechanics, vol. 70, 2003, pp. 839-851. 